\title{
Sharing Economic Policy Orientation and Policy Implementation Resistance in China
}

\author{
Cheng Shang ${ }^{1}$, Jie Chen ${ }^{2}$, Yiheng Song ${ }^{2}$, Jiashun Chen ${ }^{3}$, Juhua Zhang ${ }^{4}$ \\ ${ }^{1}$ School of Economic \& Management, Southeast University, Nanjing, China \\ ${ }^{2}$ School of Civil Engineering, Southeast University, Nanjing, China \\ ${ }^{3}$ School of Computer Science and Engineering, Southeast University, Nanjing, China \\ ${ }^{4}$ School of Transportation, Southeast University, Nanjing, China
}

\section{Email address:}

cshang98@hotmail.com (Cheng Shang), Chenjie_98@hotmail.com (Jie Chen), songyih@seu.edu.cn (Yiheng Song), cjiashun06@gmail.com (Jiashun Chen), zhangjuhua8023@163.com (Juhua Zhang)

\section{To cite this article:}

Cheng Shang, Jie Chen, Yiheng Song, Jiashun Chen, Juhua Zhang. Sharing Economic Policy Orientation and Policy Implementation Resistance in China. Science Innovation. Vol. 8, No. 1, 2020, pp. 27-31. doi: 10.11648/j.si.20200801.18

Received: February 24, 2020; Accepted: April 1, 2020; Published: April 17, 2020

\begin{abstract}
To study the establishment of the sharing economy system in China more effectively and accurately, this paper systematically sorted out the development of sharing economy in many areas such as knowledge and skills, transportation, housing, and Internet crowdfunding, and summarized the progress of China's sharing economy policy. On this basis, the development direction of this field was emphasized. This paper pointed out: 1) The development of sharing economy in various fields has the commonalities and also has its individuality in specific fields. 2) Due to the lag of the existing government policy, it cannot play a good role in monitoring and restricting the sharing economy mode in the future. For sharing economy to become regulated, orderly, sustainable and healthy, relevant government departments need to formulate targeted sharing economy policies based on the development status and future trends of various types of sharing economy modes in various regions. 3) During the development process of China's sharing economy, there are problems such as lack of social integrity, incomplete legal coverage, and personal information security, which has hindered the implementation of government policies. To solve these problems, laws and regulations with local characteristics in accordance with the specific conditions of each region should be introduced. At the same time, individuals, social groups, and sharing platforms must abide by relevant laws and regulations to help sharing economy together. This paper thereby lays a foundation for the development of sharing economy in China.
\end{abstract}

Keywords: Sharing Economy, Government Attitude, Taxation Management, Government Orientation, Implementation of Resistance

\section{中国共享经济政策导向与政策推行阻力}

商铖 ${ }^{1}$, 陈杰 $^{2}$, 宋毅恒 ${ }^{2}$, 陈嘉顺 ${ }^{3}$, 张菊花 $^{4}$

1 东南大学经济管理学院, 南京, 中国

东南大学土木工程学院, 南京, 中国

${ }^{3}$ 东南大学计算机科学与工程学院, 南京, 中国

${ }^{4}$ 东南大学交通学院, 南京, 中国

\section{邮箱}

cshang98@hotmail.com（商铖）, Chenjie_98@hotmail.com（陈杰）, songyih@seu. edu. cn（宋毅恒）,

cjiashun06@gmail.com (陈嘉顺), zhang juhua8023@163. com（张菊花） 


\begin{abstract}
摘要: 为了更加有效精准地研究共享经济体系在中国的建立, 本文系统地梳理了共享经济在知识技能、交通出行、房 屋住宿、网络众筹等众多领域的发展状况，并从中总结了中国共享经济政策进展情况。在此基础上，重点对这个领域 发展方向进行了展望。文中指出：1）共享经济在各领域的发展，具有共享经济的共性，也有在特定领域的个性。2） 由于政府现有政策具有一定的滞后性，不能在未来一段时间内对共享经济模式起到良好的监督约束作用。为了共享经 济能够规范有序、持续健康发展, 政府相关部门需要结合各地区多种类型的共享经济模式的发展现状和未来发展趋势 来制定有针对性的共享经济的政策。3）中国共享经济在发展过程中存在着社会诚信缺失、法律覆盖不全、个人信息安 全等问题, 导致政府政策推行受阻。为了解决这些问题，应当结合各地区的具体情况，推出有当地特色的法律法规。 同时个人、社会群体、共享平台都要遵守相关法规, 共同助力共享经济。期望本文能为共享经济政策体系的构建起到 抛砖引玉之用。
\end{abstract}

关键词: 共享经济, 政府态度, 税收管理, 政府导向, 推行阻力

\section{1. 引言}

在传统社会中，朋友或熟人之间物品的共用，算是初态 的共享, 这种共享以实物为主，过程中没有产生报酬和利润 [1]。2000年之后, 随着互联网 web2.0时代的到来, BBS、论 坛等纷纷涌现, 用户们也开始在网络平台上与陌生人共享信 息。2010年前后国外Uber、Airbnb[2]，国内滴滴打车、快的 打车、小猪短租等一系列实物共享平台的出现, 再到之后ofo、 摩拜等共享单车企业的成立[3], 都标志着共享经济正式进入 大众视野，并已逐步渗透到交通、住宿、金融、餐饮等众多 领域 [4]。

共享经济产业扩张迅猛, 相关企业数量和规模都呈 现快速增长的态势 [1]: 交通出行领域: ofo、摩拜、滴 滴快车、Uber; P2P网贷领域: 人人贷、宜信; 网络众 筹领域: 追梦网、大家投、众筹网; 房屋住宿领域: 蚂 蚁短租、小猪短租、途家网; 交运物流领域: 58 到家、 人人快递.......近年来, 随着共享经济规模不断扩大, 众 多专家学者对共享经济都有专业见解, 这对共享经济体 系的构建有很大作用。2011年, 王振家 [5]提出共享经济 的本质在于通过共享的方式提高产品的使用价值, 而非 产品本身。2013年, G Zervas[6]等人的研究证明共享经 济有可能改变社会福利, 共享经济可以成为新工作创造 者。2015年, 汤天波等[7]认为共享经济影响着已有的生 产模式、消费模式和商业运营模式, 是 “互联网+”下 的颠覆性经济模式, 更是未来全球经济的发展趋势; 卢 希鹏 [8]从时间的角度提出了共享经济的全新战略思维: 随经济。2016年, 秦海涛[9] 认为共享经济是利用闲置资 源或服务, 去中介化, 通过共享平台动态定价, 由双向 约束机制相互评价的一种新商业模式。2017年, 刘蕾等 [10]认为传统经济模式到共享经济模式, 其本质是一个 “去中介化” 和 “再中介化” 的过程。结合综述中国专 家研究成果, 笔者总结共享经济的共性问题, 以推进共 享经济体系的建立。

限于篇幅, 为了能够对所涉及的内容作较为全面的 阐述，本文就从政府态度、税收机制、治安管理这三个 方面对共享经济政策导向进行阐述，以期对各地政府相 关部门提出有效建议。希望能对共享经济政策体系构建 抛砖引玉。

\section{2. 共享经济在各领域的发展现状}

共享经济作为席卷全球的新兴经济模式, 迅速、多维、 立体发展。其规模不断扩大, 涉及的领域越来越多, 从最 开始的共享知识, 到后来的共享交通, 以及共享房屋、生 活用品、物流等。由此可见, 共享经济在各领域的发展, 有共享经济的共性，也有在特定领域的个性。

\section{1. 共享经济现状之知识技能}

共享经济在知识技能领域的代表企业有: 猪八戒网、 知乎、名医主刀、豆瓣网等 $[1]$ 。这些企业或平台把互联网 上的所有技术、能人分类整合到平台中, 需求者通过平台 就能马上找到与自己目标相匹配的知识技能, 利用别人的 特长来帮助用户解决遇到的各种难题, 实现知识技能的实 时共享。共享技能是时代趋势, 是刚性需求, 通过共享技 术和智慧可以帮助更多有需要的人充分利用资源。共享技 能使得每个人掌握的知识和技能得到更高效的配置和利 用，减少资源浪费。

\section{2. 共享经济现状之交通出行}

共享经济在交通出行领域的代表企业有滴滴出行、 Uber、ofo、摩拜等。共享出行主要是交通工具及交通技 术共享。这些企业通过平台在地区投放一定量的共享交通 工具, 需要使用这些交通工具的用户通过平台认证获得权 限后即可随时使用。

共享交通使得人们的出行更加便利, 更加绿色环保, 同时降低了出行成本。对于交通体系而言, 共享交通的出 现增加了交通供给规模、提升了交通供给质量, 并且带动 了相关产业的发展 [11]。值得注意的是, 共享交通在便利 了人们出行的同时, 也引发了一系列问题, 比如共享单车 乱停乱放、共享平台挪用用户押金、网约车乘客的安全问 题等。

\section{3. 共享经济现状之房屋住宿}

共享经济在房屋住宿领域的代表企业有蚂蚁短租、小 猪短租、途家网等。共享房屋顾名思义就是房屋共享, 房 主在相关平台登记房屋信息, 租客在平台选定自己心仪的 房屋进行租赁。共享房屋的出现使得房主的闲置房屋得以 
充分利用并从中可获得一定报酬, 房客则可以在出行时以 较低成本解决住宿问题。目前共享房屋的在线房源种类涵 盖了民宿、公寓、房车、四合院、木屋、树屋、帐篷等。 共享房屋给人们的出行带来便利的同时也存在一些安全 问题, 比如部分房主恶意泄露房客个人信息、部分房屋硬 件设施不合格、安全卫生不达标等。

\section{4. 共享经济现状之网络众筹}

共享经济中的网络众筹领域的代表平台有众筹网、点 名时间、追梦网等。网络众筹即有创造力的资金缺乏者通 过相关众筹平台发起众筹, 对筹资者故事和回报感兴趣且 有能力的人对发起人进行资金援助。网络众筹低门槛, 无 论身份、地位、职业、年龄、性别, 只要有想法、有创造 能力都可以发起众筹; 网络众筹多样化, 所涉及的项目包 括设计、科技、音乐、视频、食品、漫画、出版游戏、摄 影等; 支持者通常是普通的草根民众、而非公司、企业或 者风险投资人。

\section{3. 政府对共享经济体系的监督政策导向}

向来政策决策都落后于市场反应, 共享经济的发展 也不例外。近年来, 共享经济飞速发展, 共享经济模式 不断完善, 但是共享经济的相关政策尚不成熟。由于政 府现有的政策有一定的滞后性，不能在未来一段时间内 对共享经济模式起到良好的监督约束作用，所以政府的 政策应该具有前瞻性, 以保证政策推行到最底层后仍具 有实施意义。为了共享经济能够规范有序、持续健康发 展, 政府相关部门需要结合各地区各种类型的共享经济 模式的发展现状和未来发展趋势来制定有针对性的共享 经济的政策。

\section{1. 建立创新友好型监管制度}

共享经济模式日䉘成熟, 逐渐成为使大众受益的经济 模式。越是这个阶段, 越要施以一定的政策约束, 以免其 违背客观经济规律。创新友好型监管, 即承认政策学习的 必要性、推动地方制定智能性政策、事前事后相结合的新 型监管模式[12]。共享经济模式与传统经济模式截然不同, 所以不能机械地套用传统的限制式监管模型[13], 应鼓励 共享平台在法律允许的范围内合理发展[14]。“橘生淮南 则为橘, 生于淮北则为枳” , 种植庄稼要因地制宜, 政府 的政策也因如此。应遵循中央政府的相关政策, 结合地方 特色, 如城市布局、气候环境等因素, 制定有利于促进当 地共享经济发展的地方政策。政府部门要对各地区共享经 济模式的未来发展有一定的预测, 制定具有前瞻性的创新 友好型监管制度。

\section{2. 引导共享经济模式自我调节}

“物极必反” 是自然的道理。共享经济飞速发展, 随 之而来的会是平台垄断、滥用优势地位、市场进入壁垒等 现象 [15]。政府部门要做的就是尽量减少这样的现象出现, 要在全面促进、使其合规、严格监管、纳入监管四种政策 导向中拿捏好分寸 [16], 引导共享经济模式自我调节, 处
理好政府、市场、社会的关系, 形成政府-市场一社会三方 协同机制[17]。同时也应监督企业、平台、个人之间的关 系[18], 保护好各方的基本利益, 形成良好的新型灵活雇 佣关系。除此之外, 企业之间的恶性竞争、平台垄断都会 导致共享经济模式的发展受阻, 政府部门的适当反垄断 [19]处理也是极为重要的。共享经济的发展应该对反垄断 法心存敬畏, 不是任何东西都适合用共享经济的模式去发 展, 要杜绝 “共享男友、共享女友”之类哗众取宠的共享 模式。政府部门就是要控制好共享经济模式发展的边界, 促进良性竞争, 避免共享经济模式的发展出现市场垄断。

\section{3. 加强税收机制促进健康发展}

税收不仅是经济问题, 更是政治问题。根据税法规 定, 只要发生的交易行为或取得所得不属于免税范围, 就负有相应的纳税义务 [20], 所以共享经济模式中的相关 交易行为都应纳税。加强税收机制, 以增强共享经济商 业模式监督管理, 从而促进共享经济健康有序发展[21]。 完善现有法规制度, 进行税务登记, 加强监督。对于共 享平台, 加强网络支付平台管理, 实行代扣代缴税款。 政府部门细化部门职能, 建立税源管理协调机制[21]。对 于个人网络平台, 建议运营商报告涉税信息, 完善个人 纳税申报制度[21]。根据不同行业的共享经济模式制定相 应的税收制度, 明确纳税主体、提高税收征管水平、制 定税收优惠政策, 涵养优质税源、加强纳税服务、最大 程度地便利纳税人等政策建议[22]。税收是国家实行宏观 经济调控的重要杜杆之一, 科学合理的税收政策对于共 享经济模式的发展是必不可少的, 纳税是每个人和企业 应尽的义务, 这样国家才会赋予我们相应的权利, 对我 们进行法律保护。

\section{4. 规范治安体系, 保障安全发展}

篗秋白有言: “本来, 生命只有一次, 对于谁都是 宝贵的。”安全事故都不是人们所乐见的。但是, 近年 来, 共享经济发展因监管体系混乱、传统打击手段失效 等而发生的安全事故甚多[23]。如未成年人骑共享单车及 共享电动车、共享类车辆乱停乱放、共享单车事故处理 不明晰、共享平台挪用押金、个人信息泄露、网约车乘 客安全问题等。对此, 政府部门可以健全平台管理模式, 完善平台保险机制、建立调节与诉讼速裁对接机制[24], 明确不同类型的共享车辆的责任承担问题，厘清法律关 系[25]。网约车类型的平台应该加强对司机的背景审查, 加强乘客信息保密度。政府部门提出相关的治安监督政 策后, 共享经济的受众群体应该积极响应, 监督未成年 人的用车情况, 规范停车, 低速安全驾驶共享车辆, 避 免共享类交通事故发生，共享平台妥善保管用户押金、 保存用户个人信息。生命诚可贵, 保障共享经济不触及 安全的底线。

\section{5. 规范移动支付保障交易安全}

移动支付的普及, 使得用户只需扫描二维码就可以 实现共享物品的租赁, 让用户与服务之间的距离缩短[26]。 用户不再需要依赖于储蓄卡, 直接通过移动支付终端完 
成与服务商的结算, 一部手机便可解决所有消费问题, 极大地提升了共享经济的可行性和用户使用的便捷性。 可见, 共享经济离不开移动支付手段, 规范移动支付可 保证共享经济模式中的交易安全。要规范移动支付体系, 需要落实银行和支付机构对共享经济平台的合规审核职 能, 加强对银行和支付机构提供网络支付服务的检查评 估。移动支付作为新型的便捷支付方式, 存在不少漏洞, 导致其被一些不法分子利用。我们在使用移动支付手段 时要和商家确认支付信息, 不给不法分子可乘之机。移 动支付的出现, 伴随着很多信用贷款平台的出现, 其中 大部分的利息与条款是不合法的, 使用时应该注意分辨, 以免陷入循环贷款中。

\section{6. 智能化大数据处理优化资源配置}

数据作为共享经济背景下的新型资源, 通过对数据 的处理、分析和挖掘, 可以谋划产业布局、优化资源配 置, 促进共享经济健康发展。共享经济模式中的交易基 本上都依赖于移动互联网, 这对于共享经济模式中大数 据的获取是很方便的, 所以在共享经济模式的发展中只 要利用好智能化大数据处理手段, 就可以极大地促进其 更好地发展。有了共享经济特定行业的数据, 可以利用 智能化大数据处理手段建立数据模型, 预测市场走向, 以便制定监督政策，促进共享经济有序发展。同时，共 享数据的选择性公开有助于社会民众对共享经济的友好 监督。

\section{4. 共享经济模式政策推行的阻力}

共享经济作为新兴事物, 总能吸引目光, 但随之而来 的也有很多问题。我国共享经济在发展过程中存在着社会 诚信缺失、法律覆盖不全、管理混乱等问题, 导致政府政 策推行受阻, 共享经济发展畸形。共享经济若要在未来更 好地全面发展, 那么解决这些问题迫在眉睫。

\section{1. 法律制度不完善}

随着互联网的快速发展、移动支付的产生, 共享经 济得以迅速发展, 与之相对应的法律法规却相对滞后, 共享经济中存在对传统行业的恶意冲击、不正当竞争导 致的市场垄断、个人信息与隐私泄露、利益纠纷等法律 问题[27]。遵纪守法是每个公民应尽的义务, 商业活动、 个人交易行为也是如此, 其基础和前提是应存有相应的 法律法规可供参照, 但是由于共享经济模式作为新兴经 济模式快速强势地进入人们的生活, 法律法规现如今并 不完善。我国目前的共享经济相关法律法规现状是制定 立体差异较大、制定形式比较随意、制定内容有冲突、 制定内容不全面[28]。共享经济的开放性提高了泄露用户 隐私的风险, 共享经济的市场结构加剧了行业垄断风险 [29]。共享经济中的消费者预付押金模式为一人一押，资 金沉淀容易引发安全隐患, 传统法律制度已不再适用于 押金保护诉求 [30]。如ofo等公司的破产，导致广大民众 都受押金之害。

\section{2. 社会诚信缺乏}

“民无信不立”, 个人不可无信, 社会更不能失信。 共享经济模式下的诚信问题不仅与每个个体有关, 更与 整个社会有关。共享经济与社会诚信的关系是：诚信为 共享经济保驾护航, 共享经济推进诚信建设 [31]。社会诚 信是整个社会生活中逐渐形成的诚实守信的社会风气, 需要民众都做到诚实守信, 遵守共享经济模式中的相关 准则。随意丢弃自行车、肆意损坏、窃为己有、企业违 规挪用押金、恶意泄露个人信息等行为都是缺乏社会诚 信理念的人所为 [32], 我们应杜绝这样的行为, 并且在他 人有相关行为时出言劝阻。政府应该规范征信渠道, 建 立信用指标评价体系，建立共享经济的个人信用信息档 案, 加强国民诚信教育 [33]。共享经济模式下个人征信法 律完善路径有: 在征信机构方面, 健全征信机构设立方 面的法律, 明确划定征信机构的法律责任; 在征信数据 方面, 健全数据共享方面的法律, 健全数据保护方面的 法律; 在失信惩戒方面, 健全惩戒步骤, 优化惩戒手段 [34]。

\section{3. 个人信息恶意泄露}

共享经济模式下, 商家为保障自身利益, 在消费者 注册或者登陆平台时会录入个人信息, 如果不被泄露, 这本是双赢的事。但是不法人员借平台漏洞挖掘商机, 滥用共享契机赚钱谋利[35], 着实令人诟病。部分原因在 于消费者对个人信息的保护意识不强, 给不法分子以可 乘之机。“支付宝年度账单事件” 就可以看出平台数据 共享背景下个人信息安全面临的挑战有：平台占有个人 信息易引发信息权属争议、平台利益多元化增加信息安 全威胁因素、用户个人信息保护意识不强导致 “冲破围 墙” 现象频发 [36]。对此, 应该允许行政规定的现行导入、 鼓励行业协会的自主发展、共享协议中消费者的信息保 留权[37]。

\section{5. 结束语}

互联网飞速发展, 移动支付方式的兴起, 共享经济的 应运而生是势不可挡的。怎样保护、引导这个势如破竹的 新生事物便是政府部门的职责。周恩来有言, “任何新生 事物在开始时都不过是一株幼苗, 一切新生事物之可贵, 就因为在这新生的幼苗中, 有无限的活力在成长, 成长为 巨人成长为力量。” 共享经济从初具维形到如今影响甚广, 是社会对这一新生事物的包容, 但为保证其健康有序发展, 也不能放任其自由生长, 需要政府的监管、法律的规制及 全民的监督。共享经济未来发展方向多元化, 政府部门需 要根据当前共享经济的发展状况和未来发展趋势制定具 有一定前瞻性的政策, 以确保共享经济在未来健康有序发 展, 同时结合各地区的具体情况, 推出有当地特色的有效 法律法规。同时个人、社会群体、共享平台都要遵守相关 法规, 才能使共享经济带给我们的便利和经济效应更大化, 这是共享经济出现的意义。 


\section{参考文献}

[1] 马强. 共享经济在我国的发展现状、瓶颈及对策 $[\mathrm{J}]$. 现代经 济探讨, 2016(10):20-24.

[2] Yang $\mathrm{S} \mathrm{B}$, Lee $\mathrm{K}$, Lee $\mathrm{H}$, et al. In Airbnb we trust: Understanding consumers' trust-attachment building mechanisms in the sharing economy [J]. International Journal of Hospitality Management, 2019, 83: 198-209.

[3] 田华. 探究当代共享经济发展中的利与弊[J]. 中国战略新 兴产业, 2017 (48): 20.

[4] Zhang $\mathrm{T} \mathrm{C}, \mathrm{Gu} \mathrm{H}$, Jahromi M F. What makes the sharing economy successful? An empirical examination of competitive customer value propositions [J]. Computers in Human Behavior, 2019, 95: 275-283.

[5] 王振家. 共享经济的商业未来[J]. 光彩, 2011(9):56-57.

[6] Zervas G, Proserpio D, Byers J W. The rise of the sharing economy: Estimating the impact of Airbnb on the hotel industry $[\mathrm{J}]$. Journal of marketing research, 2017, 54 (5): 687-705.

[7] 汤天波，吴晓隽．共享经济:“互联网+”下的颠覆性经济模 式[J]. 科学发展, 2015(12):78-84.

[8] 卢希鹏.随经济:共享经济之后的全新战略思维 [J].人民论 坛·学术前沿,2015(22):35-44.

[9] 秦海涛. 共享经济商业模式探讨及在我国进一步发展的建 议[J]. 商业经济研究, 2016(24):124-126.

[10] 刘蕾，漂章华. 共享经济一从一"去中介化"到"再中介化"的 被动创新[J]. 科技进步与对策, 2017, 34(7):14-20.

[11] 张广厚. 我国共享交通发展对策研究 $[\mathrm{C}] / /$ 创新驱动与智慧 发展—2018年中国城市交通规划年会论文集. 2018.

[12] 陈元志. 面向共享经济的创新友好型监管研究[J]. 管理世 界, 2016(8):176-177.

[13] Fang Z, Huang L, Wierman A. Prices and subsidies in the sharing economy $[\mathrm{J}]$. Performance Evaluation, DOI: 10.1016/j.peva.2019.102037.

[14] 李勇, 何方, 方珂等. 共享经济的发展与政策推进一以 杭州市为例 [J]. 浙江社会科学, 2017(9):107-113.

[15] 吴宇飞. 共享经济的反竞争风险及政策应对 $[\mathrm{J}]$. 现代管理 科学, 2018(4): 18-20.

[16] 许荻迪. 共享经济政策目标, 政策导向与体系优化 [J]. 改 革, 2018 (4): 92-101.

[17] 秦铮,王钦.分享经济演绎的三方协同机制:例证共享单车 [J]. 改革,2017(5):124-134.
[18] 袁文全, 徐新鹏. 共享经济视阈下隐蔽雇佣关系的法律规 制[J]. 政法论坛, 2018(1):119-130.

[19] Mark Anderson, Max Huffman, 时建中等. 共享经济遇上反 垄断法:Uber是公司,还是卡特尔,或是介于两者之间?[J]. 竞 争政策研究, 2018(3):7-38.

[20] 李波, 王金兰. 共享经济商业模式的税收问题研究 [J]. 现 代经济探讨, 2016(5):29-33.

[21] 茅孝军. 共享经济下兼职收入的税法规制——兼评《法国 共享经济税收法案》[J]. 地方财政研究, 2018 (7): 36-42.

[22] 陈宇，李锐. 我国分享经济税收问题研究 [J]. 中央财经大 学学报, 2017(08):5-14.

[23] 乔桐. 浅析交通类共享经济引发的治安问题及治理 [J]. 北 京警察学院学报, 2017(6):31-36.

[24] 张路瑶, 薛智胜. 共享单车事故责任的法律分析 [J]. 法制 与社会, 2017(29):51-52.

[25] 钱茗. 共享单车使用中的责任承担问题研究 [J]. 中国商论, 2018 (10): 177-178.

[26] 王淑珍.共享经济发展过程中存在的风险点以及防范处置 措施——基于移动支付视角 [J]. 甘肃金融,2018(11):37-38.

[27] 张晶晶.我国共享经济现状及其存在的法律问题[J]. 现代商 贸工业,2018,39(36):128-129.

[28] 何琳,张颖.我国共享单车立法规制路径研究[J].湖北工业大 学学报,2018,33(3):44-47.

[29] 崔可欣. 共享经济的法律风险与规制 [J]. 经济 师,2018(11):76-77.

[30] 苏盼.共享经济预付押金模式的法律挑战与应对 [J].武汉大 学学报(哲学社会科学版),2018,71(6):160-167.

[31] 武振坤,陈晓春.共享经济与诚信的关系及相关问题的对策 [J].电子商务,2018(8):8-9.

[32] Cheng X, Fu S, Sun J, et al. An investigation on online reviews in sharing economy driven hospitality platforms: A viewpoint of trust [J]. Tourism Management, 2019, 71: 366-377.

[33] 刘乐新.共享经济是一次生动的国民诚信教育[J].思想政治 工作研究,2017(7):29-30.

[34] 卜晓颖. 个人征信法律亟待完善 [J]. 人民论 坛,2018(31):92-93.

[35] 舒心萍. 警惕“共享账号”成个人信息泄露新源头 $[\mathrm{N}]$. 中国 商报,2018-10-30(P02).

[36] 李帅.平台数据共享视阈下个人信息保护机制的构建 $[\mathrm{J}]$.贵 州师范大学学报(社会科学版),2018(2):142-150.

[37] 倪东璐,华颖杰,徐亦骁等.有关共享单车用户个人信息存在 的问题及对策研究 [J].法制博览,2018(13):56. 